\title{
Gebe bir hastada psoas kası apsesi
}

\author{
Psoas muscle abscess in a pregnant patient \\ Ersin Çintesun ${ }^{1}$ Özlem Seçilmiş Kerimoğlu ${ }^{1}$ (D) \\ Emine Uysal ${ }^{2}$ (D) \\ Huriye Ezveci ${ }^{1}$ \\ Ayşe Gül Kebapçılar ${ }^{1}$ \\ Çetin Çelik ${ }^{1}$ D \\ ${ }^{1}$ Selçuk Üniversitesi, Kadın Hastalıkları ve Doğum Anabilim Dalı, Konya, Türkiye \\ ${ }^{2}$ Selçuk Üniversitesi, Radyoloji Anabilim Dalı, Konya, Türkiye
}

\section{Öz}

Psoas kas apsesi gebelikte çok nadir görülen ve teşhisi zor bir hastalıktır. Literatürde az sayıda vaka bildirimi mevcuttur. Bu olgu sunumunda, psoas apsesi tanısı konmuş 30. gebelik haftasında olan, perkütan drenaj ve antibiyoterapi ile tedavi edilen bir hastayı sunmayı amaçladık. Psoas kas apsesi, geç tanı almaları sebebiyle, yüksek morbidite ve mortaliteye sahip bir hastalıktır. Uzun süreli ve inatçı bel ağrısı olan hastalarda ayırıcı tanıda psoas kas apsesi düşünülmelidir.

Anahtar Sözcükler: Psoas kası apsesi, gebelik, morbidite, mortalite.

\begin{abstract}
Psoas muscle is very rare and difficult to diagnose in pregnancy. There are few cases reports in the literature. In this case report, we aimed to present a patient who was diagnosed with psoas abscess and was treated with percutaneous drainage and antibiotherapy in the 30th week of gestation. Psoas muscle abscess is a disease with high morbidity and mortality due to late diagnosis. In patients with long-standing and persistent low back pain, the psoas muscle should be considered in differential diagnosis.
\end{abstract}

Keywords: Psoas muscle abscess, pregnancy, morbidity, mortality.

\section{Giriş}

Psoas kas apsesi, gebelerde oldulça nadir görülen ve tanısı zor bir hastalıktır. Literatürde az sayıda olgu bildirilmiştir (1-3). Primer ve sekonder olmak üzere iki tipi bulunmaktadır. Primer apse hemotojen yolla yayılan patojenlerle oluşurken; sekonder apse ise direct komşuluk yoluyla yayılan patojenlerle oluşur. Gastrointestinal sistem hastalıkları (Crohn hastalığı, apandisit, divertikülit gibi), osteomyelit, pyelonefrit, tüberküloz en yaygın sekonder abse nedenleridir. Psoas kas apselerinde $S$. aureus, E. coli, Bacteroides, ve Enterokoklar sıklıkla izole edilen patojenlerdir.

Tanı klinik şüphe, fizik muayene, mikrobiyolojik ve radyolojik inceleme metodları kullanılarak konmaktadır. $\mathrm{Bu}$ olguda, gebe bir hastada tanı konmuş ve tedavi edilmiş bir psoas kas apsesi olgusunu tartışmayı amaçladık.

Yazışma Adresi: Ersin Çintesun

Selçuk Üniversitesi, Kadın Hastalıkları ve Doğum Anabilim Dalı, Konya, Türkiye

E-mail: ersincintesun@gmail.com

Makalenin Geliş Tarihi: 02.01.2018 Kabul Tarihi: 15.05.2018

\section{Olgu Sunumu}

On dokuz yaşında, 30. gebelik haftasında, multipar bir kadın bir aydır devam eden ve son iki gündür yürüme ile şiddetlenen sağ lomber bölge ağrısı ile hastanemize başvurdu. Hikayesinde bulantı, kusma, ishal gibi eşlik eden bir şikayetinin olmadığını ifade etti.

Fizik muayenede subfebril ateş $\left(37,5^{\circ} \mathrm{C}\right)$ ve hafif taşikardi (90-95/dk arası) tespit edildi. Solunum, kardiyovasküler ve santral sinir sistemi muayenelerinde herhangi bir patolojik bulgu saptanmadı. Abdomen muayenesinde şiddetli gerginlik ve sağ hipokondriyak bölgede şişkinlik saptandı. Uterus yaklaşık 30 haftalık bir gebelik cesametindeydi. Sağ bacağın hiperekstansiyonu sınırlı ve ağrılıydı. Laboratuvar incelemesinde; C-reactive protein (CRP): 18,4 mg/dL, beyaz kan hücresi (WBC); $15800 \mathrm{~K} / \mathrm{uL}$, prokalsitonin; $0,415 \mathrm{ng} / \mathrm{mL}$ ve hemoglobin: $9,8 \mathrm{~g} / \mathrm{dL}$ olarak ölçüldü. Karaciğer ve böbrek normal aralıkta ölçüldü. Tam idrar analizi ve idrar kültürü normaldi. Obstetrik ultrasonografide (USG), fetal anatomi ve gelişim normaldi. Tahmini fetal ağırlık $1577 \mathrm{~g}$ olarak ölçüldü. Servikal dilatasyon ve uterus kontraksiyonu gözlenmedi.

Abdominal USG ve ileri inceleme için yapılan manyetik rezonans görüntülemede (MRG) sağ lomber bölge ve 
psoas kasından subkutan dokuya kadar uzanan $12 \times 14$ $\mathrm{cm}$ ebatlarında apse tespit edildi. Ayrıca sağ böbrekte grade 2 hidronefroz saptandı.(Şekil-1a-1b)
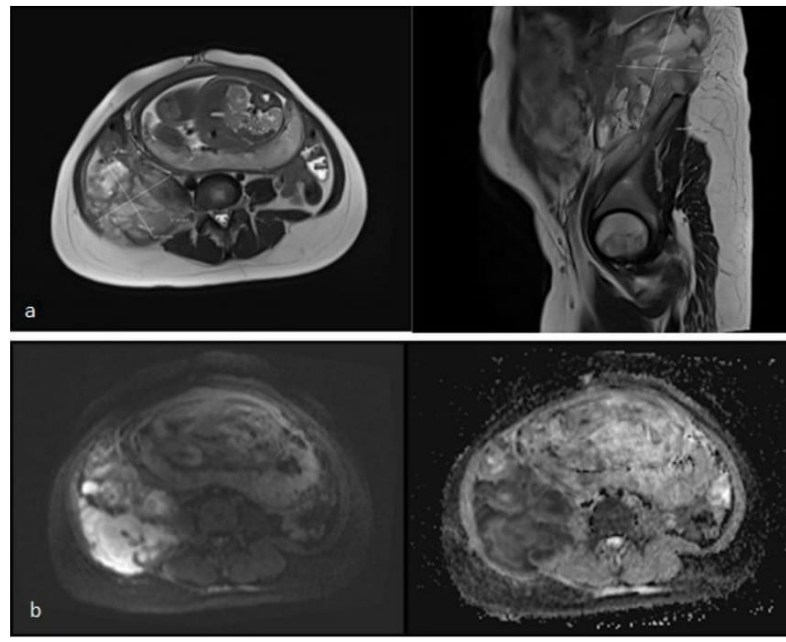

Şekil-1. a.T2 ağırlıklı MRG, b.Difüzyon ve ADC MRG. ADC: Aşikar difüzyon katsayısı, MRG: Manyetik rezonans görüntüleme

Olguya psoas kası apsesi tanısı kondu. Girişimsel radyoloji tarafından ultrason eşliğinde perkütan drenaj uygulandı ve apse lojuna dren yerleştirildi. Abse içeriğinden aerobik ve anaerobik kültürler gönderildi. Geniş spectrum enfeksiyoz ajanlara yönelik antibiyoterapi için piperasilin-tazobactam $3 \times 4,5 \mathrm{~g}$ başlandı. Ayrıca tüberküloz için kültür ve seroloji gönderildi. Apse kültüründe ESBL pozitif $E$. coli üredi. Antibiyogramda mevcut antibiyotiğe direnç saptanması üzerine antibiyotik meropenem $3 \times 1$ g/gün olarak değiştirildi. Drenden 24 saat boyunca herhangi bir püy gelmemesi üzerine dren 12. günde çekildi. Meronem tedavisi 14 güne tamamlandı ve hastanın herhangi bir ek şikayeti olmaması, laboratuvar ve klinik bulgularının tamammen gerilemesi üzerine taburcu edildi. Yatışı esnasında düzenli fetal takiplerinde de bir problem yaşanmadı. Taburcu sonrası 1. ayda bakılan renal USG'de sağ böbrekte grade 2 hidronefrozun devam ettiği gözlendi.

Hastadan tıbbi verilerinin yayınlanabileceğine ilişkin yazılı onam belgesi alındı.

\section{Tartışma}

Psoas kası abdominal ve pelvik yapılarla yakın komşuluktadır. Bu sebeple bu bölgeye yakın bir enfeksiyon odağı posterior mediastinuma ve anterior uyluğa yayılım gösterebilir. Psoas kası, uyluğa kalça ekleminden fleksiyon yaptırır ve lumbar pleksus ile innerve edilir (T12-L5). Bu yüzden psoas kası patolojileri lumbar bölgede, uyluk hareketlerinde, yürümede ağıı ile abdominal ve kasıkta gerginlik gibi semptomlara sebep olur.

Bel ağrısı, üçüncü trimesterdeki gebe kadınların yaklaşık yarısında rapor edilmiştir (4). Bel ağrısı gebelerde sık görülen bir semptom olduğundan tanıda gecikmelere sebep olabilir. Olgumuzda 1 aydır bel ağrısı olmasına rağmen, abse boyutu $14 \mathrm{~cm}$ ebatına ulaşıncaya kadar tanı konulamamıştır.

Primer psoas kası apsesi genç erkek hastalarda daha sık görülür. Olguların çoğunda tespit edilebilir bir etyoloji bulunamaz ve olguların \%83'ü 30 yaşın altındadır (5). Bu olguların hematojen yolla enfekte olduğu düşünülmektedir ve en sık Staphylococcus aureus üretilmiştir (5). Primer psoas kas apselerin aksine, sekonder apseler ek hastalığı olan yaşlı grubun hastalığıdır. Olguların \%80'i gastrointestinal sistem (Crohn hastalığı, apandisit, divertikülit) kaynaklıdır (6). Olguların geri kalanında ise etiyoloji perinefrik apse, osteomyelit, spinal kord tüberkülozu ve postoperatif kaynaklıdır. Sekonder psoas kas apselerinde barsak flora bakterileri ( $E$. coli, Bacteroides ve enterokoklar) sıklıkla kültürde üremektedir (6). Olgumuzun genç olması, bilinen bir hastalığının olmaması sebebiyle öncelikle tanıda primer psoas kas apsesini düşündürmektedir. Ancak hastanın apse kültüründe $E$. coli üremesi sebebiyle tanı konulamamış bir sekonder psoas kas apsesi de tam olarak dışlanamaz. Doğum sonrası gastrointestinal ve üriner sistemin detaylı incelenmesi uygun olacaktır.

Spinal tüberkülozu olan hastalarda Mycobacterium tuberculosis de psoas kas apsesi sebebi olabilir. Olgumuzda kültür ve seroloji incelemeleri sonrası tüberküloz tanısı dışlandı.

Psoas kas apsesinin klasik semptomatik triadı, bel ağrısı, topallama ve persistan ateştir (1). Ürolojik ve gastrointestinal semptomlar olabilir, ancak bunlar nadirdir (1). Kalça fleksiyonu sırasında artan ağrı, psoas kas apsesi için tipiktir (pozitif psoas işareti). Skolyoza neden olabilen paravertebral spazm, intraperitoneal enfeksiyondan ziyade retroperitoneal bir enfeksiyonun belirtisidir. (1). Olgumuzda sırt ağrısı, yürüme zorluğu ve subfebril ateşi vardı. Skolyoz ve paravertebral spazm gözlenmedi. Hastanın hikayesinde inatçı ateş yoktu. Başvuru esnasında subfebril ateş mevcuttu. Ayrıca hastada gözlemlenen subfebril ateş de enfeksiyona veya hastadaki anemiye bağlı oluşmuş olabilir.

Bazı vakaların tanısında düz radyografiler yararlı olabilir, ancak gebelik sırasında (özellikle erken gebeliklerde) abdominal radyografilerden kaçınılması önerilir. USG oldukça etkili bir tanı aracıdır. MRG, daha iyi yumuşak doku görüntülemesi ve radyasyon gerektirmemesi nedeniyle, gebelikte psoas kas apsesi tanısı için yararlı bir araçtır ve USG ile tanı konulamayan hastalarda kullanılabilir. Apse drenajına yardımcı olmak için gerekirse ultrason veya bilgisayarlı tomografi (BT) kullanılabilir. Olgumuzda USG ve MRG apse tanısı için kullanıldı ve USG eşliğinde apse drenajı yapıldı.

Psoas kas apsesinin tedavisi için antibiyotik ve drenaj önerilmektedir. İlk antibiyotiklerin seçiminde; primer 
olgularda stafilokoklara, sekonder olgularda ise gram negatif enterik basiller ve anaeroblara başlanmalıdır (5). Literatürde, sadece antibiyoterapi ile düzelen vakalara rağmen, yüksek mortalite ve morbidite riskinden dolayı erken apse drenajı önerilmektedir (3). Apse drenajı için perkütan veya açık girişimsel yöntemler tercih edilebilir. Perkütan drenaj daha az invaziv fakat daha uzun hastanede kalış gerektiriyor (7). Olgumuzda USG kılavuzluğunda perkütan drenaj yapıldı. Apse drenajından sonra hastanın semptomlarında hızlı iyileşme gözlendi.

Sonuç olarak, psoas kas apsesi tanısı zor ve bu nedenle yüksek morbidite ve mortalite riski taşıyan bir hastalıktır. Uzun süreli ve inatçı bel ağrısı olan hastalarda, ayırıcı tanıda psoas kas apsesi düşünülmelidir.

\section{Kaynaklar}

1. Gezer A, Erkan S, Saygi Erzik B, Erel CT. Primary psoas muscle abscess diagnosed and treated during pregnancy: Case report and literature review. Infect Dis Obstet Gynecol 2004;12(3-4):147-9.

2. Swanson A, Lau KK, Kornman T, Wallace EM, Polyakov A. Primary psoas muscle abscess in pregnancy. Aust N Z J Obstet Gynaecol 2008;48(6):607-8.

3. Kadambari D, Jagdish S. Primary pyogenic psoas abscess in children. Pediatr Surg Int 2000;16(5):408-10.

4. Kristiansson $P$, Svardsudd K, von Schoultz B. Back pain during pregnancy: A prospective study. Spine 1996;21(6):702-9.

5. Ricci MA, Rose FB, Meyer KK. Pyogenic psoas abscess: Worldwide variations in etiology. World J Surg 1986;10(5):834-43

6. Saylam K, Anaf V, Kirkpatrick C. Successful medical management of multifocal psoas abscess following cesarean section: Report of a case and review of the literature. Eur J Obstet Gynecol Reprod Biol 2002;102(2):211-4.

7. Dinç $\mathrm{H}$, Önder Ç, Turhan AU, et al. Percutaneous catheter drainage of tuberculous and nontuberculous psoas abscesses. Eur $\mathrm{J}$ Radiol 1996;23(2):130-4. 